\title{
UTILIZAÇÃO DE RESÍDUOS AGROINDUSTRIAIS PARA A PRODUÇÃO DE PROTEASES PELO TERMOFÍLICO Bacillus SP EM FERMENTAÇÃO SUBMERSA: OTIMIZAÇÃO DO MEIO DE CULTURA USANDO A TÉCNICA DE PLANEJAMENTO EXPERIMENTAL
}

\author{
Silvania Alves Ladeira, Marcela Vicente Vieira Andrade, Andréia Boechat Delatorre, Victor Haber Perez* e Meire Lélis \\ Leal Martins \\ Laboratório de Tecnologia de Alimentos, Centro de Ciências e Tecnologias Agropecuárias, Universidade Estadual do Norte \\ Fluminense, Av. Alberto Lamego, 2000, 28013-602 Campos dos Goytacazes - RJ, Brasil
}

Recebido em 27/2/09; aceito em 30/7/09; publicado na web em 21/1/10

\begin{abstract}
PROTEASE PRODUCTION USING AGROINDUSTRIAL RESIDUES BY THERMOPHILIC Bacillus sp IN SUBMERGED FERMENTATION: OPTIMIZATION OF THE CULTURE MEDIUM USING AN EXPERIMENTAL DESIGN APPROACH. Thermophilic Bacillus sp. SMIA-2, produced protease when grown on apple pectic, whey protein and corn step liquor medium, whose concentration was varied from 3 to $10 \mathrm{gL}^{-1}$, according to the central composite design $2^{3}$. The experiments were conducted in shaker, at $50{ }^{\circ} \mathrm{C}, 150 \mathrm{rpm}$ and initial $\mathrm{pH}$ 6.5. The results revealed that the culture medium affected both, cell growth and enzyme production. After graphical and numerical optimization procedure, the enzyme production reached its maximum value at $30 \mathrm{~h}$ fermentation, reaching, approximately, $70 \mathrm{U}_{\text {protein }} \mathrm{mg}^{-1}$, suggesting that this process was partially associated to the growth.
\end{abstract}

Keywords: protease; Bacillus sp.; fermentation.

\section{INTRODUÇÃO}

Proteases são enzimas que catalisam a clivagem das ligações peptídicas de proteínas e que apresentam grande importância do ponto de vista industrial, sendo utilizadas em diversas atividades como no processamento de alimentos, bebidas, formulação de detergentes, processamento de couro e pele, amaciamento de carnes, formulação de medicamentos, indústria têxtil, entre outros. ${ }^{1-5}$

Devido à promissora aplicabilidade das proteases e ao seu alto custo de obtenção, sua produção deve ser intensificada utilizandose para esse fim, meios de cultura de baixo custo, ${ }^{6}$ levando em consideração que aproximadamente 30 a $40 \%$ do custo envolvido na sua produção está relacionado ao meio de cultura utilizado para o crescimento do micro-organismo. Nesse contexto, em escala industrial, exoenzimas como as proteases alcalinas são produzidas com meios de cultura complexos, contendo glicose e outros substratos de alto custo. Portanto sua otimização é de grande importância para a definição de alternativas de produção economicamente viáveis. ${ }^{7-10}$

Nos últimos anos, uma diversidade de subprodutos da indústria agrícola ou resíduos agroindustriais têm sido estudados com a finalidade de formular substratos para produção de protease. ${ }^{7}$ Por exemplo, soro de queijo, pectina e água de maceração de milho são resíduos provenientes da agroindústria que apresentam grande potencial de reuso devido a sua composição e características físico-químicas, além dos benefícios ambientais. Aproximadamente, $80 \%$ do volume do leite destinado à fabricação de queijos correspondem a soro gerado. No Brasil são produzidos cerca de 1.000.000 t/ano de soro, resultando em 7500 t de proteínas de soro de queijo. ${ }^{11}$ Por outro lado, a água de maceração de milho, a qual provem principalmente da fabricação de óleo de milho, constitui uma fonte rica de carboidratos, aminoácidos, peptídeos, minerais, metais, vitaminas e fosfato. ${ }^{12}$ Nesta mesma linha de raciocínio, a pectina, como seu nome sugere, é uma das substâncias pécticas caracterizada por macromoléculas glicosídicas de alto peso molecular. Estas substâncias pécticas correspondem a até $4 \%$ do peso de resíduos agroindustriais, como cascas de frutas. ${ }^{13,14}$

As proteases podem ser extraídas de diversos organismos, incluindo bactérias, fungos, leveduras, tecidos de mamíferos e de plantas. Porém, uma grande proporção das proteases disponíveis comercialmente é derivada atualmente de linhagens de Bacillus, por serem estes organismos produtores de quantidade substancial de protease extracelular. ${ }^{1,2,15}$ No entanto, não foi definido um meio de cultura ideal que propicie uma máxima produção de protease microbiana, porque cada micro-organismo apresenta condições diferentes de cultivo para uma produção ótima da protease. Sendo assim, a composição do meio de cultura e a concentração de seus componentes têm que ser otimizadas de acordo com o microorganismo utilizado. ${ }^{15,16}$

A otimização dos processos biotecnológicos de produção é um tema de grande importância. Em processos fermentativos, qualquer melhoria alcançada na produtividade do metabolismo microbiano, em geral, através da manipulação dos parâmetros físico- químicos e nutricionais pode alterar significativamente o rendimento do produto de interesse. Esta otimização pode ser conseguida, por exemplo, através de metodologias estatísticas. ${ }^{1}$ De fato, diversos trabalhos publicados têm abordado a metodologia de superfície de resposta como ferramenta na otimização do processo de produção enzimática de protease. ${ }^{1,16-18}$ Alguns destes focaram sua atenção sobre o papel de uma variedade de fontes de carbono e nitrogênio na produção destas enzimas. Melaço de cana-de-açúcar, extrato de malte, extrato de levedura, licor de milho, farinhas, cascas de batata e penas de aves foram algumas das fontes estudadas para a produção de proteases. ${ }^{1,7,15}$

O presente trabalho teve como objetivo otimizar a produção de proteases por uma espécie termofílica Bacillus sp. SMIA-2, utilizando como substratos a pectina de maçã, proteínas do soro de queijo e água de maceração de milho. 


\section{PARTE EXPERIMENTAL}

\section{Micro-organismo}

O micro-organismo utilizado neste estudo foi Bacillus sp. SMIA2, uma bactéria termofílica, isolada no Laboratório de Tecnologia de Alimentos (LTA) da Universidade Estadual Norte Fluminense Darcy Ribeiro (UENF) a partir de amostras de solo do município de Campos dos Goytacazes-RJ. ${ }^{19}$ Segundo estes autores, os resultados da comparação das sequências de $16 \mathrm{~S}$ rRNA indicaram que o isolado possui $94 \%$ de similaridade com B. caldoxylyticus e Bacillus sp. espécie AK1. O micro-organismo foi conservado em meio TSY (triptona $20 \mathrm{~g} \mathrm{~L}^{-1}$; $\mathrm{NaCl} 10 \mathrm{~g} \mathrm{~L}^{-1}$; extrato de levedura $10 \mathrm{~g} \mathrm{~L}^{-1}$; ágar $20 \mathrm{~g} \mathrm{~L}^{-1}$ e água $1 \mathrm{~L}$ ) sob temperatura de refrigeração.

\section{Preparação do meio de cultura e condições de fermentação}

A composição do meio de cultura utilizado para a produção da protease foi $\left(\mathrm{g} \mathrm{L}^{-1}\right)$ : pectina de maçã (variável), proteínas de soro de queijo (variável), água de maceração de milho (variável), peptona $(0,1) ; \mathrm{KCl}(0,03) ; \mathrm{K}_{2} \mathrm{HPO}_{4}(0,09) ; \mathrm{MgSO}_{4}(0,05) ; \mathrm{CaCl}_{2}(0,03)$; $\mathrm{ZnO}\left(2,5 \times 10^{-3}\right) ; \mathrm{FeCl}_{3} \cdot 6 \mathrm{H}_{2} \mathrm{O}\left(2,7 \times 10^{-2}\right) ; \mathrm{MnCl}_{2} \cdot 4 \mathrm{H}_{2} \mathrm{O}\left(1,0 \times 10^{-2}\right)$; $\mathrm{CuCl}_{2} \cdot 2 \mathrm{H}_{2} \mathrm{O}\left(8,5 \times 10^{-4}\right) ; \mathrm{CoCl}_{2} \cdot 6 \mathrm{H}_{2} \mathrm{O}\left(2,4 \times 10^{-3}\right) ; \mathrm{NiCl}_{3} \cdot 6 \mathrm{H}_{2} \mathrm{O}(2,5$ $\left.\mathrm{x} 10^{-4}\right) ; \mathrm{H}_{3} \mathrm{BO}_{3}\left(3,0 \times 10^{-4}\right) . \mathrm{O} \mathrm{pH}$ final do meio foi ajustado para 7,5 com $\mathrm{NaOH}$ e posteriormente esterilizado em autoclave a $121^{\circ} \mathrm{C}$ por $15 \mathrm{~min}$. Uma vez preparado o meio de cultura, este foi inoculado com $0,5 \mathrm{~mL}$ de um pré-inóculo preparado no dia anterior. Os experimentos foram realizados em triplicata, em frascos Erlenmeyers de $250 \mathrm{~mL}$, contendo $25 \mathrm{~mL}$ do meio, usando um shaker orbital (Thermo Forma Orbital Shaker, Ohio, USA) a $150 \mathrm{rpm}$ e à temperatura de $50^{\circ} \mathrm{C}$.

\section{Planejamento experimental e análise estatística}

Para avaliar os efeitos das concentrações de pectina de maçã, proteínas de soro de queijo e água de maceração de milho na produção de protease $\left(\mathrm{Y}_{1}\right)$ e no crescimento celular $\left(\mathrm{Y}_{2}\right)$, foi realizado um planejamento central composto $2^{3}$, com seis repetições no ponto central para estimativa do erro experimental e usando pontos estrelas (Tabela 1), durante $24 \mathrm{~h}$ de fermentação à temperatura de $50^{\circ} \mathrm{C}$ e $150 \mathrm{rpm}$.

A análise da significância dos efeitos das variáveis independentes sobre a produção de protease foi avaliada através do programa Statistica, versão 7.0 (StatSoft Co., USA), enquanto que o programa Design Expert versão 5.0 foi empregado para realizar a análise da variância (ANOVA) dos resultados obtidos, assim como para realizar os procedimentos de otimização gráfica e/ou numérica. Neste contexto, o teste $F$ foi empregado como critério de validação da significância estatística dos modelos obtidos ao nível de confiança de $95 \%$.

\section{Métodos analíticos}

\section{Determinação do crescimento celular}

O crescimento celular foi determinado, após 24 h de fermentação, em função da densidade óptica a $600 \mathrm{~nm}$, utilizando-se um espectrofotômetro Hitachi modelo UVmini-1240 (Kyoto, Japão).
Determinação da produção de protease através de ensaio enzimático

A produção de protease foi determinada indiretamente através da avaliação da atividade proteolítica de extratos brutos do caldo de fermentação. Desta forma, quando concluídas as fermentações, os meios de culturas foram centrifugados a $4500 \mathrm{x}$ g por $15 \mathrm{~min}$ a $4{ }^{\circ} \mathrm{C}$ em uma centrífuga modelo Hermle Z382K, e o sobrenadante livre de células foi utilizado para dosagem da atividade da enzima. A atividade da protease foi determinada em triplicata nos filtrados da cultura, adicionando-se $0,5 \mathrm{~mL}$ de extrato enzimático bruto em $1,0 \mathrm{~mL}$ de substrato contendo azocaseína a 0,2\% dissolvida em tampão Tris-HCL(0,2 M; pH 8,5) a $70{ }^{\circ} \mathrm{C}$ por $10 \mathrm{~min}$. A reação foi paralisada pela adição de $0,5 \mathrm{~mL}$ de ácido tricloroacético $15 \%$ (TCA) à mistura que foi centrifugada (Hermle Z382K) a $15000 \mathrm{~g}$ por $5 \mathrm{~min}$ a $4{ }^{\circ} \mathrm{C}$ e o sobrenadante colocado em tubos de ensaio contendo $0,5 \mathrm{~mL}$ de uma solução de $\mathrm{NAOH} 1 \mathrm{~N}$. A coloração desenvolvida foi medida por meio de espectrofotômetro Shimadzu UV-mini 1240, utilizando comprimento de onda de $420 \mathrm{~nm}$.

$\mathrm{O}$ mesmo procedimento foi realizado com o controle, exceto que o TCA foi adicionado antes do extrato enzimático. Uma unidade de protease foi definida como a quantidade de enzima necessária para produzir um aumento na absorbância, a $420 \mathrm{~nm}$, igual a $0,1 \mathrm{em} 60$ min. ${ }^{20} \mathrm{~A}$ concentração de proteínas foi determinada pelo método de Lowry, com as modificações propostas por Petterson ${ }^{21}$ com vistas a expressar a taxa de reação em termos de atividade específica.

\section{RESULTADOS E DISCUSSÃO}

Na Tabela 2 são apresentados os resultados referentes à cinética de crescimento microbiano e da atividade de protease, de acordo com o planejamento experimental realizado em shaker. Os valores de atividade da protease produzida, expressos em unidades da enzima por massa de proteína ( $\mathrm{U} \mathrm{mg}^{-1}$ de proteína), variaram de 0,2 a 55 . Neste caso, o melhor resultado (ensaio 1) foi alcançado após $24 \mathrm{~h}$ de incubação da cultura contendo $3,0 \mathrm{~g} \mathrm{~L}^{-1}$ de pectina de maçã, $3,0 \mathrm{~g} \mathrm{~L}^{-1}$ de proteínas de soro de queijo e $3,0 \mathrm{~g} \mathrm{~L}^{-1}$ de água de maceração de milho.

Shikha et $a l .{ }^{10}$ relatam a produção de proteases utilizando uma diversidade de fontes de carbono e nitrogênio. Segundo estes autores, os melhores resultados foram encontrados quando se utilizou o melaço de cana-de-açúcar $\left(245 \mathrm{U} \mathrm{mL}^{-1}\right)$ como fonte de carbono e farelo de trigo (155 $\mathrm{U} \mathrm{mL}^{-1}$ ) como fonte de nitrogênio. Apesar da relevância do trabalho destes autores e do atrativo de terem empregado resíduos agroindustriais como meio de cultura, é difícil estabelecer critérios de comparação a respeito dos valores de protease alcançados pelos mesmos e aqueles obtidos no presente trabalho, uma vez que seus resultados não foram expressos em termos de atividade específica.

Para analisar a significância dos efeitos das variáveis independentes estudadas, inicialmente foram feitas análises visando verificar alterações no crescimento celular e na produção da enzima. Neste contexto, os resultados ilustrados no gráfico de Pareto (Figura 1) revelaram que as condições que favoreceram o crescimento celular foram diferentes daquelas que estimularam a produção da protease, sugerindo que a obtenção desta enzima não acontece através de um processo bioquimicamente simples. Desta forma, verificou-se uma influência negativa, porém estatisticamente significativa das três variáveis independentes ao nível de 95\% de confiança (Figura 1a).

Tabela 1. Matriz experimental do planejamento central composto 23 com pontos estrelas

\begin{tabular}{lccccc}
\hline Variáveis & Código & \multicolumn{3}{c}{ Níveis } & \\
& & $-1,682$ & -1 & 0 & +1 \\
\hline Pectina de maçã $\left(\mathrm{g} \mathrm{L}^{-1}\right)$ & $\mathrm{X}_{1}$ & 0,62 & 3,0 & 6,5 & 10,0 \\
Proteína de soro de queijo $\left(\mathrm{g} \mathrm{L}^{-1}\right)$ & $\mathrm{X}_{2}$ & 0,62 & 3,0 & 6,5 & 12,4 \\
Água de maceração de milho $\left(\mathrm{g} \mathrm{L}^{-1}\right)$ & $\mathrm{X}_{3}$ & 0,62 & 3,0 & 6,5 & 10,0 \\
\hline
\end{tabular}


Tabela 2. Resultados do planejamento central composto $2^{3}$ com pontos estrelas, para a produção de protease e crescimento microbiano do Bacillus sp. SMIA-2

\begin{tabular}{lccccc}
\hline $\mathrm{N}^{\circ}$ exp. & $\mathrm{X}_{1}$ & $\mathrm{X}_{2}$ & $\mathrm{X}_{3}$ & $\mathrm{Y}_{1}$ & $\mathrm{Y}_{2}$ \\
\hline 1 & $-1,000$ & $-1,000$ & $-1,000$ & 54,71 & 1,232 \\
2 & 1,000 & $-1,000$ & $-1,000$ & 0,204 & 0,23 \\
3 & $-1,000$ & 1,000 & $-1,000$ & 27,07 & 0,269 \\
4 & 1,000 & 1,000 & $-1,000$ & 0,736 & 0,222 \\
5 & $-1,000$ & $-1,000$ & 1,000 & 34,59 & 1,014 \\
6 & 1,000 & $-1,000$ & 1,000 & 1,207 & 0,211 \\
7 & $-1,000$ & 1,000 & 1,000 & 25,82 & 0,331 \\
8 & 1,000 & 1,000 & 1,000 & 21,92 & 0,523 \\
9 & $-1,682$ & 0,000 & 0,000 & 29,85 & 0,523 \\
10 & 1,682 & 0,000 & 0,000 & 0,53 & 0,035 \\
11 & 0,000 & $-1,682$ & 0,000 & 40,23 & 1,017 \\
12 & 0,000 & 1,682 & 0,000 & 21,67 & 0,263 \\
13 & 0,000 & 0,000 & $-1,682$ & 38,15 & 0,699 \\
14 & 0,000 & 0,000 & 1,682 & 23,59 & 1,146 \\
15 & 0,000 & 0,000 & 0,000 & 31,89 & 0,669 \\
16 & 0,000 & 0,000 & 0,000 & 32,91 & 0,845 \\
17 & 0,000 & 0,000 & 0,000 & 32,44 & 0,669 \\
18 & 0,000 & 0,000 & 0,000 & 30,72 & 0,669 \\
19 & 0,000 & 0,000 & 0,000 & 31,71 & 0,544 \\
20 & 0,000 & 0,000 & 0,000 & 31,05 & 0,544 \\
\hline & & & & &
\end{tabular}

Um aumento nas concentrações da pectina de maçã, das proteínas do soro de queijo e da água de maceração de milho resultou em uma redução na produção de protease, sendo que a concentração de pectina foi a variável que, a princípio, apresentou comparativamente um efeito mais acentuado. Contudo, vários pesquisadores relataram resultados contrários em termos da significância de efeitos das fontes de carbono e nitrogênio sobre a produção de proteases, usando a ferramenta de planejamento de experimentos, ${ }^{1,6,22}$ embora isto dependa claramente da grandeza ou das faixas de concentração das variáveis estudadas e da forma de expressar ou quantificar a produção enzimática. Por exemplo, Chauhan e Gupta ${ }^{6}$ concluíram que níveis mais altos de concentração de amido e um hidrolisado de caseína foram propícios para uma maior produção de proteases e, semelhantemente, Reddy et al. ${ }^{1}$ obtiveram os melhores resultados quando utilizaram níveis mais altos de amido de milho e água de maceração de milho como substratos. No entanto, quando a combinação ou a interação entre as variáveis, isto é, as concentrações de pectina, da proteína de soro de queijo e da água de maceração de milho foram avaliadas em função da análise simultânea dos efeitos destas interações, observaram-se efeitos significantes e positivos sobre a produção enzimática (Figura 1a), ou seja, houve um aumento da quantidade da atividade do extrato enzimático do caldo de fermentação. Por outro lado, ao analisar a influência de cada variável independente sobre o crescimento celular, observou-se que a concentração da água de maceração de milho, embora estatisticamente significante, não mostrou um efeito marcante quando comparado com a interação entre a concentração de pectina e proteínas do soro, cuja combinação resultou na obtenção de maiores valores de concentração celular.

Subsequentemente, visando realizar um estudo integral da influência das variáveis independentes sobre o crescimento celular e a produção de protease, valores experimentais e preditos foram comparados com equações empíricas ajustadas com auxílio da análise de variância (ANOVA) usando o software Design Expert v. 5.0.
Para isto, o critério de hierarquia foi levado em consideração e as equações obtidas para predizer a produção de protease (Equação 1) e crescimento celular (Equação 2) são apresentadas em função dos termos codificados das variáveis independentes.

$$
\begin{aligned}
& Y_{1}=31,93-12,26 X_{1}-3,40 X_{2}-1,73 X_{3}-6,82 X_{1}^{2}-1,25 X_{2}^{2}-1,28 X_{3}^{2}+ \\
& 7,21 X_{1} X_{2}+5,44 X_{1} X_{3}+4,88 X_{2} X_{3} \\
& Y_{2}=0,66-0,18 X_{1}-0,19 X_{2}+0,064 X_{3}-0,16 X_{1}^{2}-0,029 X_{2}^{2}+0,071 X_{3}^{2} \\
& +0,24 X_{1} X_{2}+0,055 X_{1} X_{3}+0,075 X_{2} X_{3}
\end{aligned}
$$
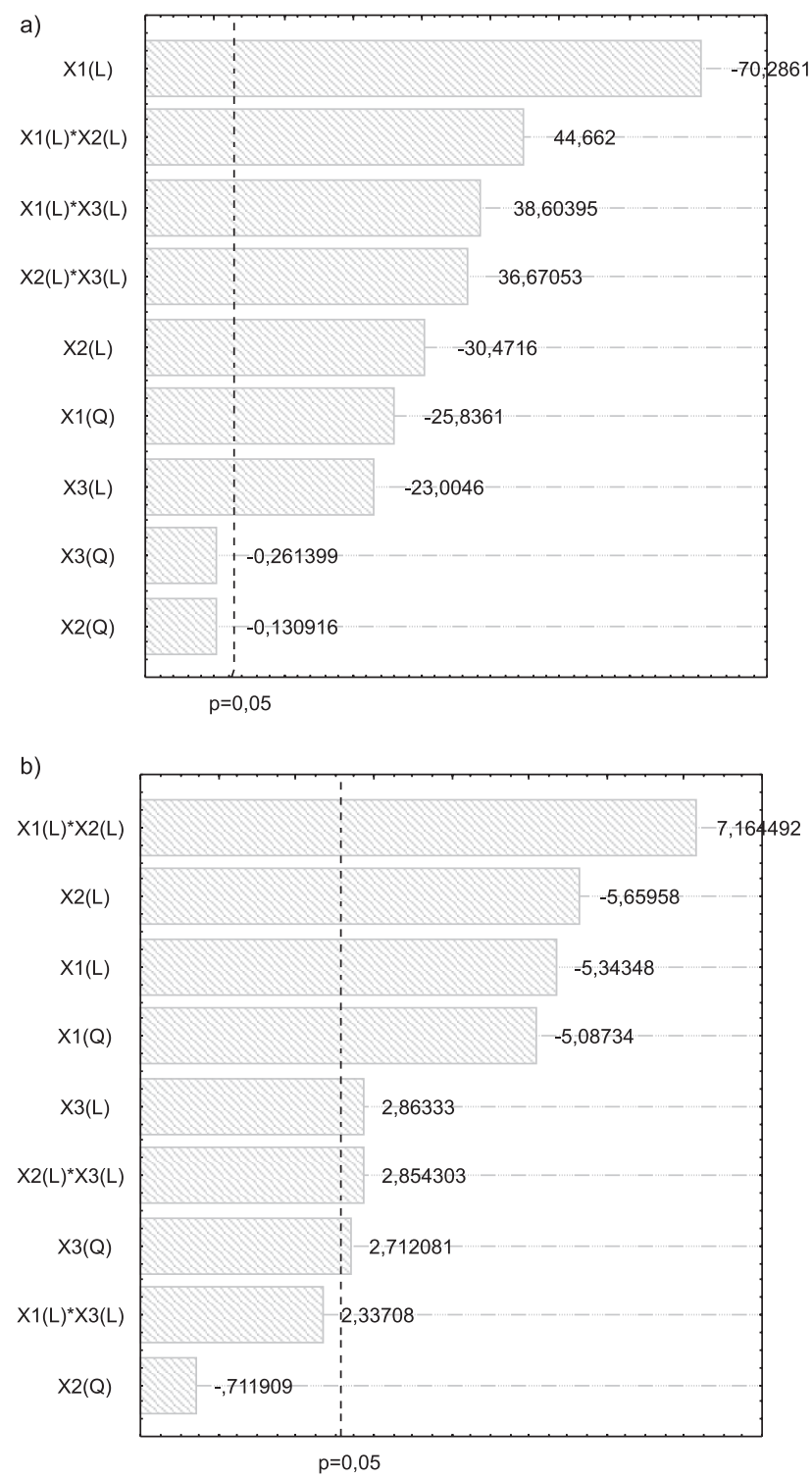

Figura 1. Efeito das variáveis independentes estudadas e de suas interações: a) produção de protease; b) crescimento microbiano (D.O. 600nm) do Bacillus sp. SMIA-2, para um nível de confiança de $95 \%(p<0,05)$

Na Tabela 3 são apresentados os resultados da análise da variância (ANOVA) ao nível de confiança de 95\% (p<0.05) para ambas as variáveis resposta, revelando que os modelos ajustados foram significantes de acordo com a análise do teste $F$, desde que o valor de probabilidade $p(0,0001)$ foi muito menor do que 0,05 . Quando o valor de $F$ calculado for maior que o tabelado para o nível de confiança adotado, há evidência estatística suficiente para supor a 
Tabela 3. Análise de variância (ANOVA) usando o programa Design Expert referente às variáveis dependentes, ao nível de confiança de 95\%

\begin{tabular}{|c|c|c|c|c|c|}
\hline Fonte da variação & Soma quadrática & Graus de liberdade & Média quadrática & $\mathrm{F}_{\mathrm{cal}}$ & $p<0,05$ \\
\hline \multicolumn{6}{|c|}{ PRODUÇÃO DE PROTEASE (U/mg de proteína) } \\
\hline Modelo & 3774,21 & 9 & 419,36 & 14,05 & 0,0001 \\
\hline Resíduo & 298,52 & 10 & 29,85 & & \\
\hline Falta de ajuste & 295,14 & 5 & 59,03 & 87,17 & $<0,0001$ \\
\hline Erro puro & 3,39 & 5 & 0,68 & & \\
\hline Total & 4072,73 & 19 & & & \\
\hline \multicolumn{6}{|c|}{ CRESCIMENTO CELULAR (D.O. 600nm) } \\
\hline Modelo & 2,02 & 9 & 0,22 & 13,41 & 0,0002 \\
\hline Resíduo & 0,17 & 10 & 0,017 & & \\
\hline Falta de ajuste & 0,11 & 5 & 0,021 & 1,73 & 0,2818 \\
\hline Erro puro & 0,061 & 5 & 0,012 & & \\
\hline Total & 2,18 & 19 & & & \\
\hline
\end{tabular}

existência de uma relação entre as variáveis. ${ }^{23}$ No entanto, notamos que no primeiro caso a falta de ajuste também significante deste modelo sugere a necessidade de se pesquisar um modelo matemático que, necessariamente, seja mais apropriado para prever a produção de protease como uma função da concentração de pectina, soro de queijo e água de maceração de milho.

No segundo caso, o modelo empírico obtido para descrever o crescimento microbiano apresentou um coeficiente de correlação $\mathrm{R}^{2}=0,92$ indicando que $92 \%$ da variabilidade da resposta poderia ser explicada pelo modelo, que confirmou a qualidade do ajuste. Este fato foi também corroborado pela não existência da falta de ajuste e pelo baixo valor de $[$ prob $<F]=0,0002$ menor que 0,05 para o modelo.

Gráficos de superfície de resposta (Figura $1 \mathrm{Sa}$ e $1 \mathrm{Sc}$, material suplementar) apresentaram a interação entre os fatores concentração de pectina de maçã e proteínas do soro, quando a concentração de água de maceração de milho se manteve constante ao nível -1. Em ambos os casos os perfis destas superfícies foram similares, sendo que região de máximos valores preditos em torno de $58,00 \mathrm{U} \mathrm{mg}^{-1} \mathrm{e}$ 1,23 D.O. $600 \mathrm{~nm}$ para atividade da protease produzida e crescimento celular, respectivamente, foram alcançados para os níveis mais baixos das variáveis independentes a $95 \%$ de confiança. No entanto, gráficos de cubo são amplamente usados para representar simultaneamente os efeitos de três variáveis junto a uma variável dependente (resposta) e, dessa forma, uma análise integral da influência das interações entre todas as variáveis independentes sobre ambas as respostas pode então ser mais bem visualizada nos gráficos de cubo ilustrados nas Figuras $1 \mathrm{Sb}$ e $1 \mathrm{Sd}$, material suplementar.

Finalmente, visando estabelecer as condições mais favoráveis para alcançar os máximos níveis de produção de protease e do crescimento celular, foi realizado um procedimento de otimização gráfica. Neste contexto, uma função objetivo definida como "desejabilidade" 24 permitiu definir uma região de trabalho, área sombreada (Figura 2), na qual valores de protease produzida acima de $58 \mathrm{U} \mathrm{mg}^{-1}$ e crescimento celular acima de 1,23 D.O. $600 \mathrm{~nm}$ podem ser alcançados simultaneamente. Ressalta-se, ainda, que esta região gráfica de trabalho basicamente é formada pela superposição das curvas dos modelos matemáticos para as variáveis dependentes $\left(\mathrm{Y}_{1}, \mathrm{Y}_{2}\right)$ de acordo com os critérios impostos, isto é, a obtenção de alto rendimento de protease produzida e de máximo crescimento do Bacillus sp., respectivamente.

Com o propósito de confirmar as condições otimizadas, novos experimentos foram conduzidos para avaliar a cinética da fermentação (Figura 3). Conforme observado, o crescimento do Bacillus foi iniciado imediatamente após sua incubação no meio de cultura, porém a secreção da enzima foi observada após 6 h de incubação.

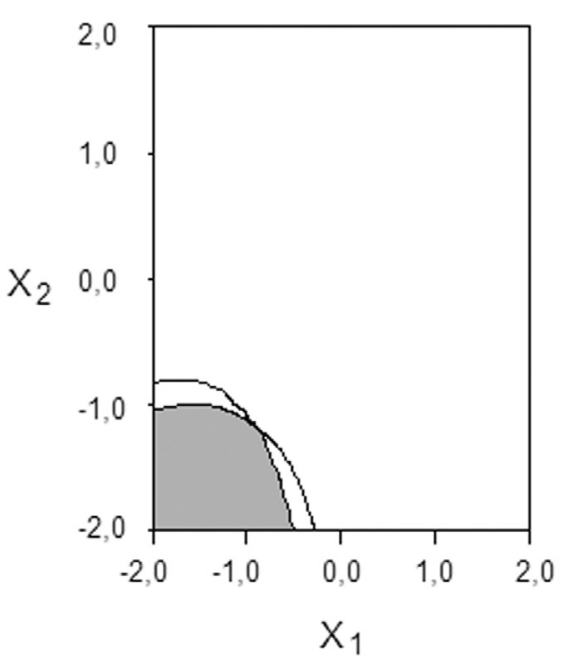

Figura 2. Otimização gráfica simultânea para a produção de protease e o crescimento celular durante fermentação em skaker do Bacillus sp. SMIA-2

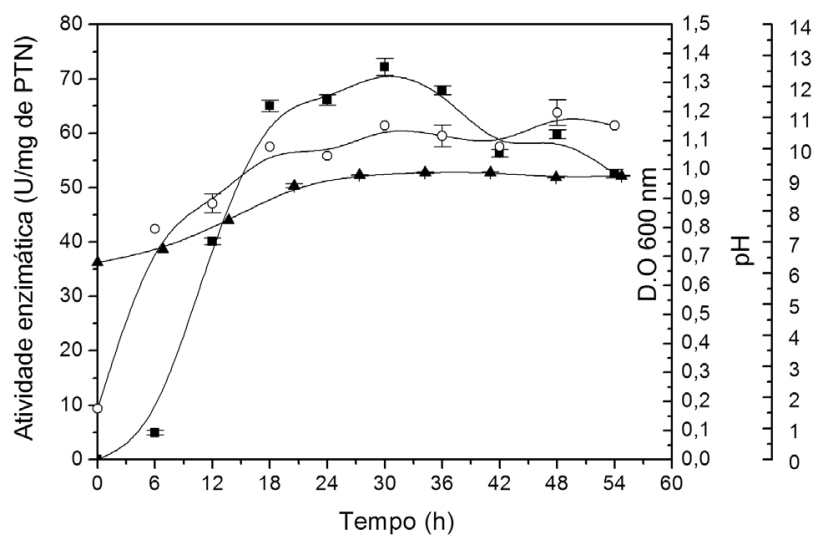

Figura 3. Cinética de crescimento celular $(\bigcirc)$, produção de protease $(\square) e$ $p H(\mathbf{\Delta})$ durante a fermentação de Bacillus sp. SMIA-2 à temperatura de 50 ${ }^{\circ} \mathrm{C}$ e 150 rpm, referente à condição de máxima produção de protease

Subsequentemente, a fase exponencial de crescimento foi visível durante as primeiras $15 \mathrm{~h}$ de fermentação. Após esse tempo, a velocidade de crescimento manteve-se constante marcando, assim, o início da fase estacionária da cultura, momento no qual se observou 
a produção máxima de protease. Esta produção mais tardia da enzima em relação ao crescimento coincidiu com um aumento moderado de pH de 6-7 para 8-9. Assim sendo, a atividade máxima de protease foi observada após $30 \mathrm{~h}$ de fermentação atingindo em torno de 65 a $70 \mathrm{U} \mathrm{mg}^{-1}$ de proteína, quando o crescimento do micro-organismo já havia cessado como dito anteriormente. Isto sugere que a indução efetiva da enzima não ocorre até que a fase estacionária seja alcançada e a fonte de carbono disponível esgotada. Subsequentemente, os níveis da enzima caíram moderadamente para aproximadamente $50 \mathrm{U} \mathrm{mg}^{-1}$ até as $54 \mathrm{~h}$ de fermentação, instante no qual foi finalizado o processo. Em trabalhos prévios, Silva et al..$^{25}$ usaram um meio de cultura semelhante empregando soro de queijo, água de maceração de milho e maltose no lugar da pectina como fonte de carbono, visando a produção de protease pelo mesmo Bacillus sp. SMIA-2. Os autores reportaram níveis de protease em torno de $50 \mathrm{U} \mathrm{mg}^{-1}$ de proteína, valor este aproximadamente 1,5 vezes menor que a produção alcançada neste trabalho usando pectina. Nesta linha de raciocínio e apenas a titulo comparativo, a atividade máxima da protease encontrada neste trabalho foi aproximadamente 5 vezes superior à atividade relatada por Nascimento et al., ${ }^{26}$ quando Bacillus sp. cresceu em meio de cultivo contento citrato trissódico como fonte de carbono e nitrato de amônio como fonte de nitrogênio. Segundo estes autores, ${ }^{26}$ os Bacillus de modo geral produzem maior quantidade de protease ao final da fase exponencial de crescimento. Uma vez que a síntese de protease está relacionada com uma elevada taxa de renovação de proteínas durante a esporulação, fatores que afetam a esporulação, como condições de estresse causadas pela redução da concentração de nutrientes, tensão de oxigênio ou composição do meio, podem ter grande efeito na produção destas enzimas. Chauhan e Gupta ${ }^{6}$ também obtiveram maior produção de protease na fase estacionária de crescimento do micro-organismo quando trabalharam com Bacillus sp. RGR-14.

\section{CONCLUSÕES}

Bacillus sp SMIA-2 mostrou a sua capacidade de produzir protease por fermentação submersa usando-se como meio de cultura pectina de maçã, proteína de soro de queijo e água de maceração de milho suplementado com micronutrientes; no entanto, as condições que favoreceram o crescimento celular foram diferentes daquelas que estimularam a produção de protease, revelando a complexa natureza deste processo.

Confirmou-se a significância estatística de todas as variáveis independentes e, desta forma, os resultados sugeriram a conveniência de se trabalhar com as mais baixas concentrações de substrato, sendo a pectina a variável que apresentou um efeito mais acentuado sobre a produção enzimática.

\section{MATERIAL SUPLEMENTAR}

No material suplementar, disponível em http://quimicanova. sbq.org.br, com acesso livre, na forma de arquivo PDF, encontra-se a Figura 1 Sa-d.

\section{AGRADECIMENTOS}

Ao apoio financeiro do CNPq e da UENF pela concessão da bolsa de mestrado.

\section{REFERÊNCIAS}

1. Reddy, L. V. A.; Wee, Y.; Yun, J.; Ryu, H.; Bioresour. Technol. 2008, 99, 2242.

2. Sellami-Kamoun, A.; Haddar, A.; Ali, N. E.; Ghorbel-Frikha, B.; Kanoun, S.; Nasri, M.; Microbiol. Res. 2008, 163, 299.

3. Genckal, H.; Tari, C.; Enzyme Microb. Tech. 2006, 39, 703.

4. Ghorbel, B.; Kamoun, A. S.; Nasri, M.; Enzyme Microb. Tech. 2003, 32 , 513.

5. Haki, G. D.; Rakshit, S. K.; Bioresour. Technol. 2003, 89, 17.

6. Chauhan, B.; Gupta, R.; Process Biochem. 2004, 39, 2115.

7. Mukherjee, A. K.; Adhikari, H.; Rai, S. K.; Biochem. Eng. J. 2008, 39, 353.

8. Joo, H. S.; Chang, C. S.; Enzyme Microb. Tech. 2006, 38, 176.

9. Kona, R. P.; Qureshi, N.; Pai, J. S.; Bioresour. Technol. 2001, 78, 123.

10. Shikha, S. A.; Darmwal, N. S.; Bioresour. Technol. 2007, 98, 881.

11. Ferreira, C. L. L. F.; Mosquim, M. C. A. V.; III Encontro Divital de Tecnologia de Laticínios, Viçosa, Brasil, 1998.

12. Rivas, B.; Moldes, A. B.; Dominguez, J. C.; Int. J. Food Microbiol. 2004, 97, 93.

13. Uenojo, M.; Pastore, G. M.; Quim. Nova 2007, 30, 388.

14. Jayani, R. S.; Saxena, S.; Gupta, R.; Process Biochem. 2005, 40, 2931

15. Rao, Y. K.; Lu, S.; Liu, B.; Tzeng, Y.; Biochem. Eng. J. 2006, $28,57$.

16. Oskouie, S. F. G.; Tabandeh, F.; Yakhchali, B.; Eftekhar, F.; Biochem. Eng. J. 2008, 39, 37.

17. Li, J.; Ma, C.; Ma, Y.; Li, Y.; Zhou, W.; Xu, P.; Appl. Microbiol. Biotechnol. 2007, 74, 563.

18. Xiao, Z. J.; Liu, P. H.; Qin, J.Y.; Xu, P.; Appl. Microbiol. Biotechnol. 2007, 74, 61.

19. Souza, A. N.; Martins, M. L. L.; Braz. J. Microbiol. 2001, 32, 271.

20. Janssen, P. H.; Peek, K.; Morgan, H. W.; Microbiol. Biotechnol. 1994, $41,400$.

21. Petterson, G. L.; Anal. Biochem. 1977, 83, 346.

22. Ramnani, P.; Kumar, S. S.; Gupta, R.; Process Biochem. 2005, 40, 3352.

23. Barros Neto, B.; Scarminio, I. S.; Bruns, R. E.; Como fazer experimentos: Pesquisa e desenvolvimento na ciência e na indústria, Ed. da Unicamp: Campinas, 2001.

24. Myers, R. H.; Montgomery, D. C.; Response Surface Methodology: Process and Product Optimization Using Designed Experiments, $2^{\text {nd }}$ ed.; Wiley-Interscience, 1999.

25. Silva, C. R.; Delatorre, A. B.; Martins, M. L. L.; Braz. J. Microbiol. 2007, 38, 253.

26. Nascimento, W. C. A.; Silva, C. R.; Carvalho, R.V.; Martins, M. L. L.; Ciênc. Tecnol. Aliment. 2007, 27, 417. 


\section{UTILIZAÇÃO DE RESÍDUOS AGROINDUSTRIAIS PARA A PRODUÇÃO DE PROTEASES PELO TERMOFÍLICO Bacillus SP EM FERMENTAÇÃO SUBMERSA: OTIMIZAÇÃO DO MEIO DE CULTURA USANDO A TÉCNICA DE PLANEJAMENTO EXPERIMENTAL}

Silvania Alves Ladeira, Marcela Vicente Vieira Andrade, Andréia Boechat Delatorre, Victor Haber Perez* e Meire Lélis Leal Martins

Laboratório de Tecnologia de Alimentos, Centro de Ciências e Tecnologias Agropecuárias, Universidade Estadual do Norte Fluminense, Av. Alberto Lamego, 2000, 28013-602 Campos dos Goytacazes - RJ, Brasil
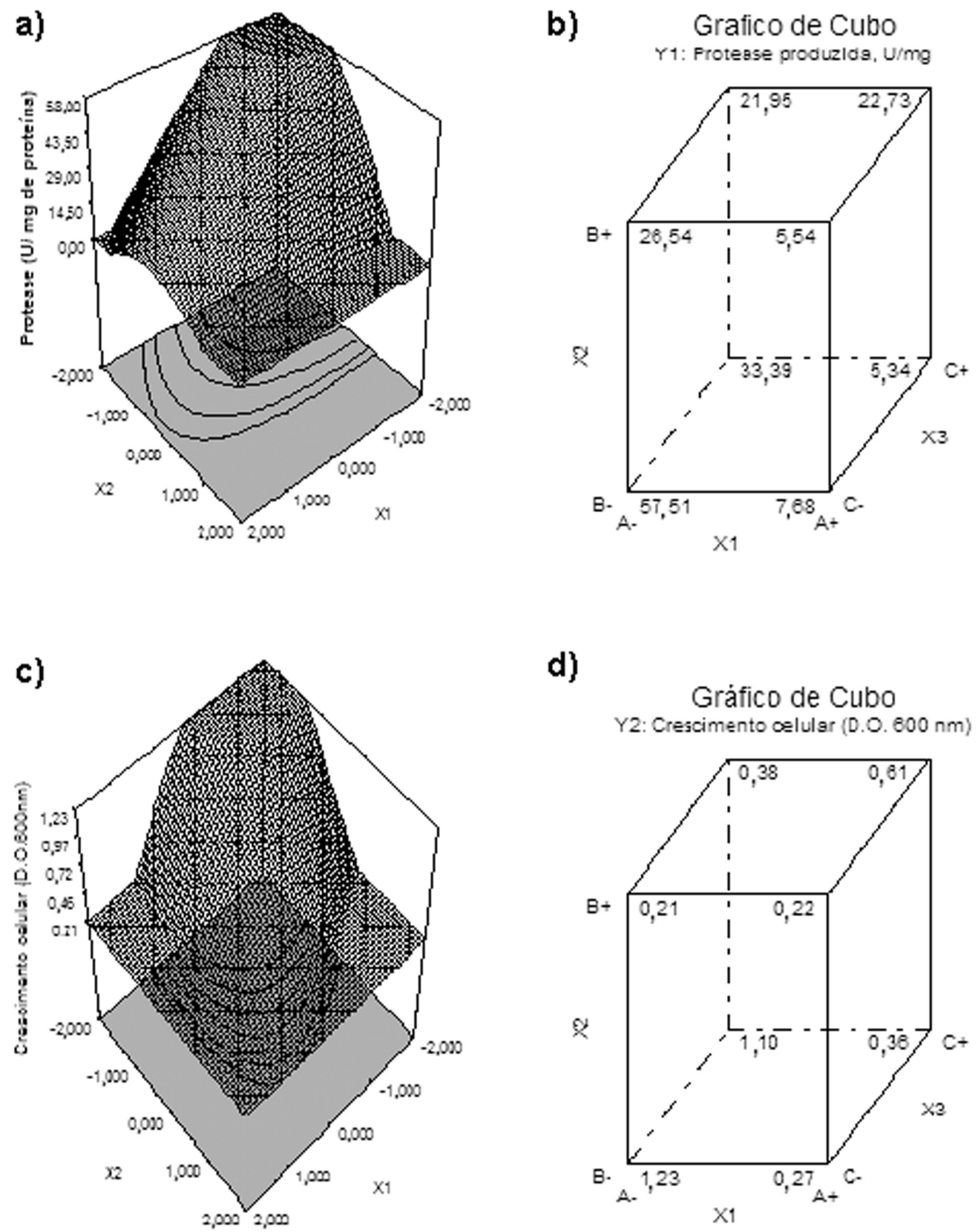

d)

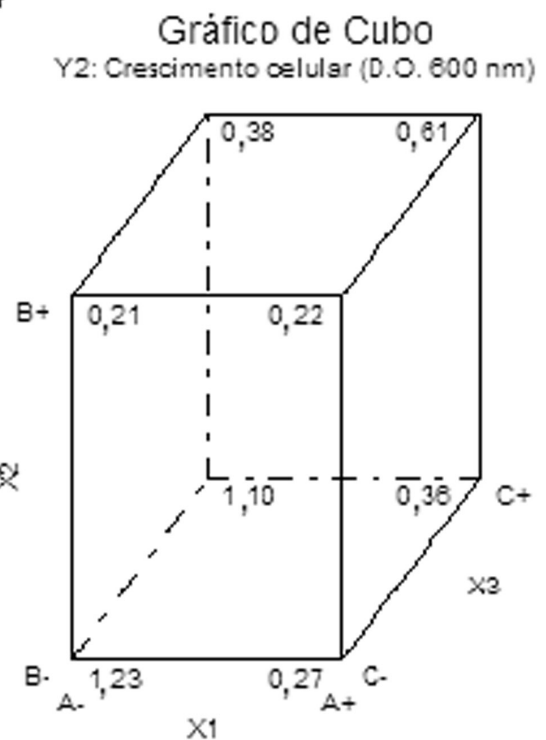

Figura 1S. Efeito da interação entre as variáveis independentes sobre a produção de protease e o crescimento celular de acordo com o planejamento experimental ao nível de $95 \%$ de confiança: a) superfície de resposta para a produção de protease $\left(X_{3}=-1\right)$; b) gráfico de cubo para a produção de protease; c) superfície de resposta para o crescimento celular $\left(X_{3}=-1\right)$; d) gráfico de cubo para crescimento celular 